\title{
Model for bridging the translational "valleys of death" in spinal cord injury research
}

\author{
This article was published in the following Dove Press journal: \\ Journal of Healthcare Leadership \\ 16 April 2014 \\ Number of times this article has been viewed
}

\author{
Bill Barrable' \\ Nancy Thorogood' \\ Vanessa Noonan ${ }^{1,2}$ \\ Jocelyn Tomkinson' \\ Phalgun Joshi' \\ Ken Stephenson' \\ John Barclay' \\ Katharina Kovacs Burns ${ }^{3}$ \\ 'Rick Hansen Institute, ${ }^{2}$ Division of \\ Spine, Department of Orthopaedics, \\ University of British Columbia, \\ Vancouver, BC, ${ }^{3}$ Health Sciences \\ Council, University of Alberta, \\ Edmonton, $A B$, Canada
}

\begin{abstract}
To improve health care outcomes with cost-effective treatments and prevention initiatives, basic health research must be translated into clinical application and studied during implementation, a process commonly referred to as translational research. It is estimated that only $14 \%$ of health-related scientific discoveries enter into medical practice and that it takes an average of 17 years for them to do so. The transition from basic research to clinical knowledge and from clinical knowledge to practice or implementation is so fraught with obstacles that these transitions are often referred to as "valleys of death". The Rick Hansen Institute has developed a unique praxis model for translational research in the field of spinal cord injury (SCI). The praxis model involves three components. The first is a coordinated program strategy of cure, care, consumer engagement, and commercialization. The second is a knowledge cycle that consists of four phases, ie, environmental scanning, knowledge generation and synthesis, knowledge validation, and implementation. The third is the provision of relevant resources and infrastructure to overcome obstacles in the "valleys of death", ie, funding, clinical research operations, informatics, clinical research and best practice implementation, consumer engagement, collaborative networks, and strategic partnerships. This model, which is to be independently evaluated in 2018 to determine its strengths and limitations, has been used to advance treatments for pressure ulcers in SCI. The Rick Hansen Institute has developed an innovative solution to move knowledge into action by bridging the "valleys of death" in the research continuum, with the intention of improving health outcomes for people with SCI and decreasing the financial impact on the health care system. This model may be generalizable to other health conditions and the lessons learned in developing the praxis model may assist other organizations dealing with similar translational research challenges.
\end{abstract}

Keywords: spinal cord injuries, clinical outcomes, translational research, implementation, knowledge mobilization, praxis model

\section{Introduction}

Spinal cord injury (SCI) is a complex medical condition that has long-term consequences, including paralysis, autonomic dysfunction, and decreased quality of life and life expectancy. Additionally, many people with SCI suffer with secondary complications, such as pressure ulcers, urinary tract infections, and pain, which not only have a significant impact on quality of life, but also result in frequent rehospitalization. ${ }^{1,2}$

$\mathrm{SCI}$ is unique in that it affects every physiological system, involves the entire spectrum of care from acute to community, and has a variety of traumatic and nontraumatic causes. Although the incidence of SCI in Canada is relatively small, with an estimated 1,785 new cases per year, ${ }^{3}$ it carries an almost catastrophic economic burden of $\$ 2.7$ billion per year for new cases of traumatic SCI. ${ }^{4} \mathrm{SCI}$ is also known as
Correspondence: John Barclay

Rick Hansen Institute, 6th Floor,

Blusson Spinal Cord Centre,

6400-818 W I0th Avenue,

Vancouver, BC V5Z IM9, Canada

$\mathrm{Tel}+\mathrm{I} 604827$ I676

Fax + I 604827 I669

Email jbarclay@rickhanseninstitute.org 
the second most expensive condition to care for, after infant respiratory distress syndrome. ${ }^{5}$

Despite decades of progress, SCI is still a complex heterogeneous condition with varying degrees of paralysis and recovery. Potential treatments involve surgical, cellular, molecular, and pharmaceutical therapies, although only surgical stabilization and removal of bone fragments and physical rehabilitation have been shown to be helpful for recovery from SCI. ${ }^{6}$ Inpatient care is costly, and substantial recovery is unusual. ${ }^{7}$ With such a serious costly condition and no obvious therapies waiting, there is considerable interest in and expectation of potential stem cell and neuroregenerative therapies, many of which have not yet been tested in humans.

The complex nature of the mechanisms and complications of SCI and the variety of physiological systems impacted also pose challenges for effective research, innovation, and development of therapeutics. The relatively small incidence of SCI in Canada means that there is limited financial motivation for private investment in research or development of therapeutics specific to SCI. As a result, research in SCI is often dependent on traditional public funders of academic research, such as the Canadian Institute of Health Research and the US National Institutes of Health. In addition, as with many conditions, there are a limited number of standardized best practices that exist for the care of people with SCI across the health care continuum (prehospital, acute, rehabilitation, and community). In many cases, standardized clinical practice guidelines that already exist lack widespread support, ${ }^{8}$ fail in the absence of a coordinated implementation strategy, ${ }^{9}$ or have some components that are not effectively used even after implementation. ${ }^{10}$ These challenges must be addressed if improvements and cost savings in the treatment and care of people with SCI are to be realized.

It is estimated that only $14 \%$ of health-related scientific discoveries enter into medical practice, ${ }^{11}$ and that it takes an average of 17 years for them to do so. ${ }^{12}$ The process of moving research into practice, commonly described as translation, ie, "the conversion of basic science to patient benefit", ${ }^{12}$ is so difficult that these obstacles to translation are often referred to as "valleys of death". ${ }^{13}$ The term "valley of death" has been most frequently used in the context of product development, particularly concerning the transfer of innovation in pharmaceuticals or technology to describe "the gap between an idea's technical invention or market recognition and the efforts to commercialize it". ${ }^{14}$ Two "valleys of death" are common in this context. The first occurs during the period of transition when a developing technology is deemed promising, but too new to validate its commercial potential and thereby attract the capital necessary for its continued development. ${ }^{15}$ The second occurs when a technology has been validated in a clinical setting and even approved for market sale and use by regulatory authorities, such as Health Canada or the US Food and Drug Administration, but is not yet approved for coverage by provincial government or private plan payers. When the term "valleys of death" was first used in health settings, it was conceptualized as a single gap, describing obstacles to bringing treatment options for patients ${ }^{16}$ from "bench to bedside". There are two "valleys of death" commonly observed in the health setting, ie, between basic and clinical research and development, and between clinical research and development and health care practice. ${ }^{12}$ Challenges posed by these "valleys of death" include transitioning from traditional granting mechanisms to other investor sources, ${ }^{16,17}$ having the new innovation covered by insurers, securing stable funding for research, ${ }^{18-20}$ and overcoming resource (funding or personnel) constraints associated with clinical practice.

Addressing these "valleys of death" has become a high priority in health research, because the failure to translate research knowledge effectively into practice is a major barrier preventing human benefit from advances in biomedical sciences. ${ }^{21}$ In health research as well as health care outcomes, this inefficiency in translation of research knowledge may mean differences between life and death, and health and disability for patients.

\section{Description of the model}

SCI has acute and chronic effects on every physiological system in the human body, so requires a collaborative, multidisciplinary approach to both research and care. ${ }^{6}$ Translational research has also been noted to be most effective using cross-disciplinary and collaborative research approaches that are not easily done in the traditional academic sphere. ${ }^{20,22}$ In the context of a strong interest among clinicians, researchers, and consumers, and a demonstrated economic rationale, the field of SCI research is primed for an innovative cross-disciplinary translational approach to move research more effectively along the continuum to benefit patient care, given the many obstacles and translational "valleys of death" described here.

The mission of the Rick Hansen Institute (RHI) is to foster greater collaboration across SCI communities and to accelerate progress toward a cure for paralysis after SCI. The organization acts as a catalyst for translational research, and brings together the best and brightest minds in SCI research, clinical care, and related services. The RHI was formed in 
2007 by a unique alliance of practice leaders and clinical researchers in SCI who found that the few funds available for SCI research in Canada were primarily directed to basic science rather than translational research informed by priority needs identified in the clinic. Furthermore, a need was identified to support all aspects of the continuum of SCI treatment and care, and to accelerate the development of new therapies with the goal of decreasing the time for research on these new therapies to be translated into real-life benefits. Basic scientists and researchers typically worked independently of one another, with no integrated national strategy or mechanism to collect and share data, set priorities, manage funds efficiently, or to standardize care across the country. ${ }^{23}$ This lack of coordination in the field between patients, clinicians, and researchers resulted in suboptimal access to new innovations or best practice for people with SCI despite the amount of resources spent on developing those innovations and best practices. With feedback from its board of directors, RHI developed an evolving praxis model as an approach to overcome the translational "valleys of death" for SCI research (Figure 1). For RHI, the praxis model is defined as a mechanism by which research on the most relevant and promising therapeutic and medical device innovations for SCI, is examined, facilitated, shared, and supported to full implementation within clinical care.

Praxis, from the Greek meaning "doing," is one of Aristotle's three basic activities of humanity resulting from knowledge. ${ }^{24}$ Praxis is described as "a goal-oriented action resulting from theoretical knowledge". ${ }^{25}$ At RHI, praxis is the process by which research knowledge is mobilized to be put into practice and support translational research. RHI offers solution-focused tools to overcome specific obstacles in the research continuum of SCI discoveries to achieve the ultimate goals of improved health care outcomes for people with SCI, such as increased mobility and decreased rehospitalization due to secondary complications, with decreased financial impact on the health care system. In fact, this is how RHI defines a return on its investment: improved clinical, health, and psychosocial outcomes for people with SCI divided by the cost of developing and implementing the innovations that lead to improved outcomes.

As shown in Figure 2, the praxis model consists of three essential components:

- a resulting coordinated program strategy, ie, the vehicle that transitions research knowledge into practice, and is focused on improving outcomes that benefit people with SCI and their clinicians

- the knowledge cycle, ie, four interrelated steps conducted in the midst of development of knowledge that act as an engine driving the research momentum toward outcomes, primarily from a clinical research perspective

- resources and infrastructure, ie, the tools to bridge the "valleys of death" by overcoming key obstacles that prevent research from reaching the bedside.

At RHI, the coordinated program strategy is advised by a translational research advisory committee consisting of experts in SCI research, clinicians, and individuals with SCI to ensure that all RHI translational research programs are aligned with the mission and vision of the institute. This committee provides a peer-stakeholder environment in which all potential RHI-supported projects are subjected to relevance criteria, ie, a predetermined evaluation process that utilizes existing Canadian and international expertise in SCI to determine the relevance of the proposals to established priority areas, as identified in Table 1. Such a multifactorial assessment ensures that RHI-supported projects have the closest possible match to the priorities of people with SCI and the best opportunity for improving outcomes in SCI. Therefore, projects supported under this framework have a better chance of making a difference to the health and well-being of people with SCI.

This coordinated program strategy is delivered through four core programs:

- Cure, focusing on generation of knowledge and establishment of treatments that will ultimately result in a cure for paralysis after SCI

- Care, focusing on ensuring equitable and optimal evidence-informed care for persons with SCI and filling important gaps in knowledge related to SCI care

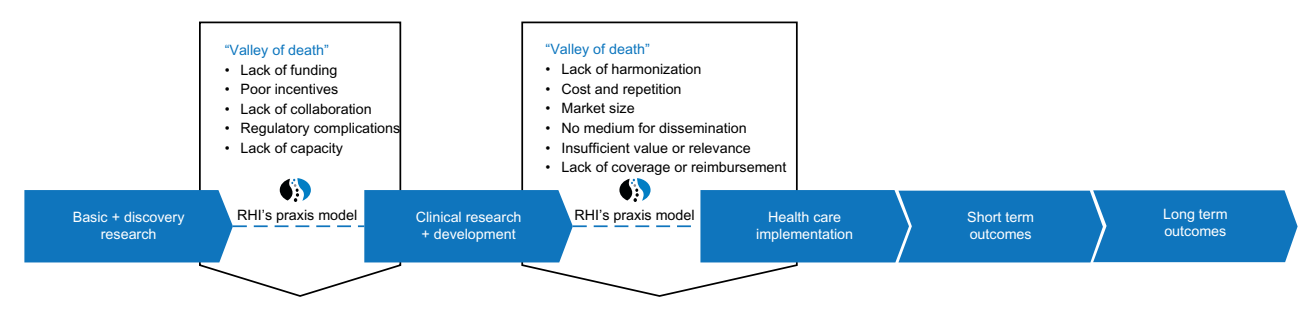

Figure I Praxis model at the Rick Hansen Institute (RHI) for bridging the "valleys of death" in spinal cord injury research and practice. 


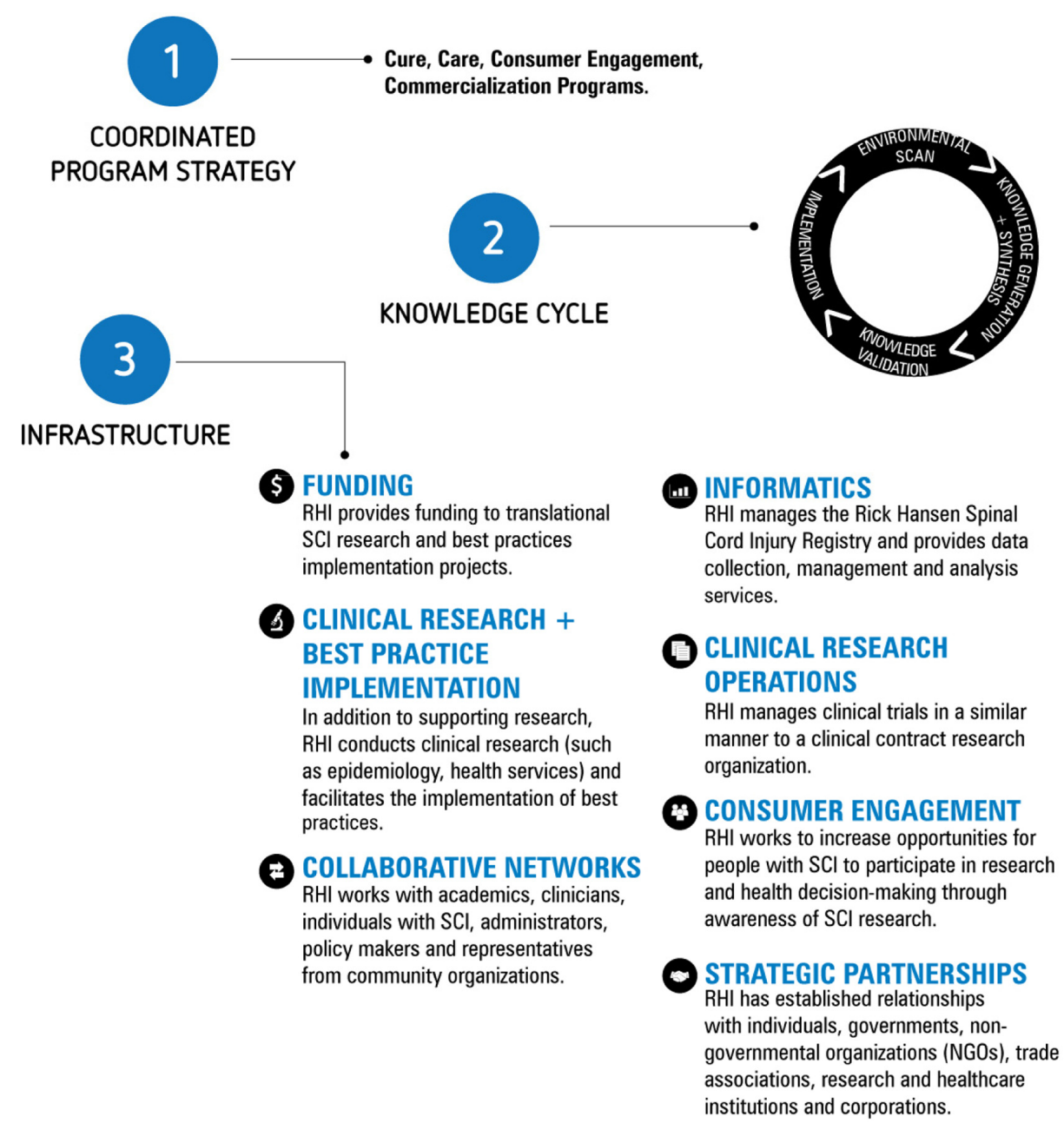

Figure 2 Three essential components of the praxis model at the RHI.

Abbreviations: $\mathrm{SCl}$, spinal cord injury; RHI, Rick Hansen Institute.

- Consumer engagement, focusing on involving more individuals with $\mathrm{SCI}$ in research

- Commercialization, focusing on facilitation of increased investment in the development of innovative precommercial therapeutics, therapeutics, medical devices, and diagnostics with application to SCI.

Each of the four core programs has its own advisory committee comprised of individuals with relevant subject matter expertise.

However, the praxis model is more than just a collection of projects or programs. This model is an approach with the potential to be generalizable to other areas of health research, wherever key obstacles to translational research exist and create "valleys of death", thereby preventing health innovations from reaching patients. The praxis model can be thought of as a process of collaborative reflection, synthesis, and implementation of knowledge that links the funnel of knowledge production described by Graham et $\mathrm{al}^{26}$ and
Haynes, ${ }^{27}$ which in this case is discovery or clinical research evidence/knowledge, with a four-phase knowledge action cycle as follows.

Phase 1: an environmental scan determines and assesses the issues facing various SCI stakeholders, to inform research efforts and provide comparative baselines against which to measure success. At RHI, this is primarily undertaken through literature reviews and surveys.

Phase 2: generation and synthesis of knowledge facilitates studies that develop new knowledge in response to key clinical needs and the gaps expressed by SCI stakeholders. This phase involves testing hypotheses and investigating the feasibility of interventions and treatments. In this phase, RHI primarily gathers and synthesizes the existing knowledge that is essential to enable translational research, such as population health data on SCI or current health care outcomes.

Phase 3: knowledge validation verifies whether the new knowledge or practice has an evidence-based justification to 
Table I Criteria for predetermined evaluation process to establish priority areas in translational research programs

Relevancy criteria

- Choosing the highest quality clinical trials based on the best available science

- Determining whether the study will benefit from the clinical trials infrastructure at the $\mathrm{RHI}$

- Impact of outcomes on stakeholders and people with spinal cord injury

- Engagement of stakeholders during the design and implementation of the project

- The probability of uptake by affected stakeholders

- The appropriateness of the knowledge translation and practice implementation plans

- Economic sustainability of practice implementation

- Opportunities for leveraging funding from multiple organizations

Abbreviation: RHI, Rick Hansen Institute.

be implemented in the care of people with SCI. Verification may involve meta-analysis of evidence in the literature, supporting pilot studies, or assessment of the effectiveness of existing clinical practices. Several validation initiatives are underway at RHI, including assessment of existing clinical practice according to a standard in collaboration with Accreditation Canada, and supporting the development of SCI Rehabilitation Evidence, an authoritative source of rehabilitation clinical evidence and outcome measure ${ }^{28}$ enabling clinicians and researchers to assess how effective their work is to improve the function and lives of people with SCI.

Phase 4: implementation of best practices translates validated knowledge into practice to improve the care of people with SCI. RHI undertakes implementation through several vehicles: development of continuous professional education modules, a knowledge mobilization network to champion implementation of validated clinical practice guidelines in SCI care, development of accreditation systems for acute and rehabilitation care, and supporting patient education by development of e-learning resources. The outcome of behavioral change in clinical practice is a long-term endeavor requiring many years of investment with careful and strategic implementation to achieve and maintain successful adoption. Therefore, RHI implementation vehicles consider the mechanisms of sustainability and challenges at an individual or organizational level that may come into play. In the experience of RHI, a combination of interventions is needed to achieve lasting changes at the levels of both patient care and systems. A final implementation vehicle, the RHI's commercialization strategy, focuses on making profitable matches between investors and innovators to facilitate the commercialization of innovations of benefit to people with SCI.
Although present as four discrete phases, one leading to the next, in reality, one phase looping back to the previous phase while proceeding to the next phase simultaneously is common. For example, new information generated from phase 2 could trigger one to go back to do further environmental scanning (phase 1) and at the same time, proceeding to phase 3 to validate this newly gained information.

The four-step knowledge cycle in the praxis model confronts many of the obstacles within the "valleys of death" by provision of critical resources and infrastructure for moving research knowledge and innovations through the continuum of research to outcomes: funding, clinical operations, informatics, research, consumer engagement, collaborative networks, and strategic partnerships. These essential tools are central to the praxis model and move a research discovery through the four phases of our knowledge cycle, and enable RHI to enter into any particular phase of the cycle to help overcome obstacles holding up promising research. See Table 2 for a description of resources and Figure 3 for the collaborative networks that the RHI fosters.

\section{Performance measurement and evaluation}

RHI has developed a performance measurement and evaluation strategy to assess the effectiveness of its praxis model. This strategy is based upon established practices, ${ }^{29-31}$ and is in line with guidance from our Canadian federal government funders. ${ }^{32}$ The theory of change elaborated within the RHI's praxis model has been summarized in the form of a logic model for the purposes of identifying results and associated performance measures. Due to the heterogeneity of activities in which the RHI engages, the logic model is designed to be simple and adaptive to all project contexts.

The outputs of the logic model correspond to the strategies of the RHI, ie, translational research, best practice implementation, informatics, network development, best and brightest, and consumer engagement. The immediate outcomes correspond to our program areas:

- SCI research accelerated toward cure

- improved standardized delivery of care across Canada and internationally

- increased development and commercialization of innovations

- increased opportunities for participation in research and health decision-making among consumers

The ultimate outcome of the logic model is encapsulated in the vision of the RHI, ie, a world without paralysis after SCI. 


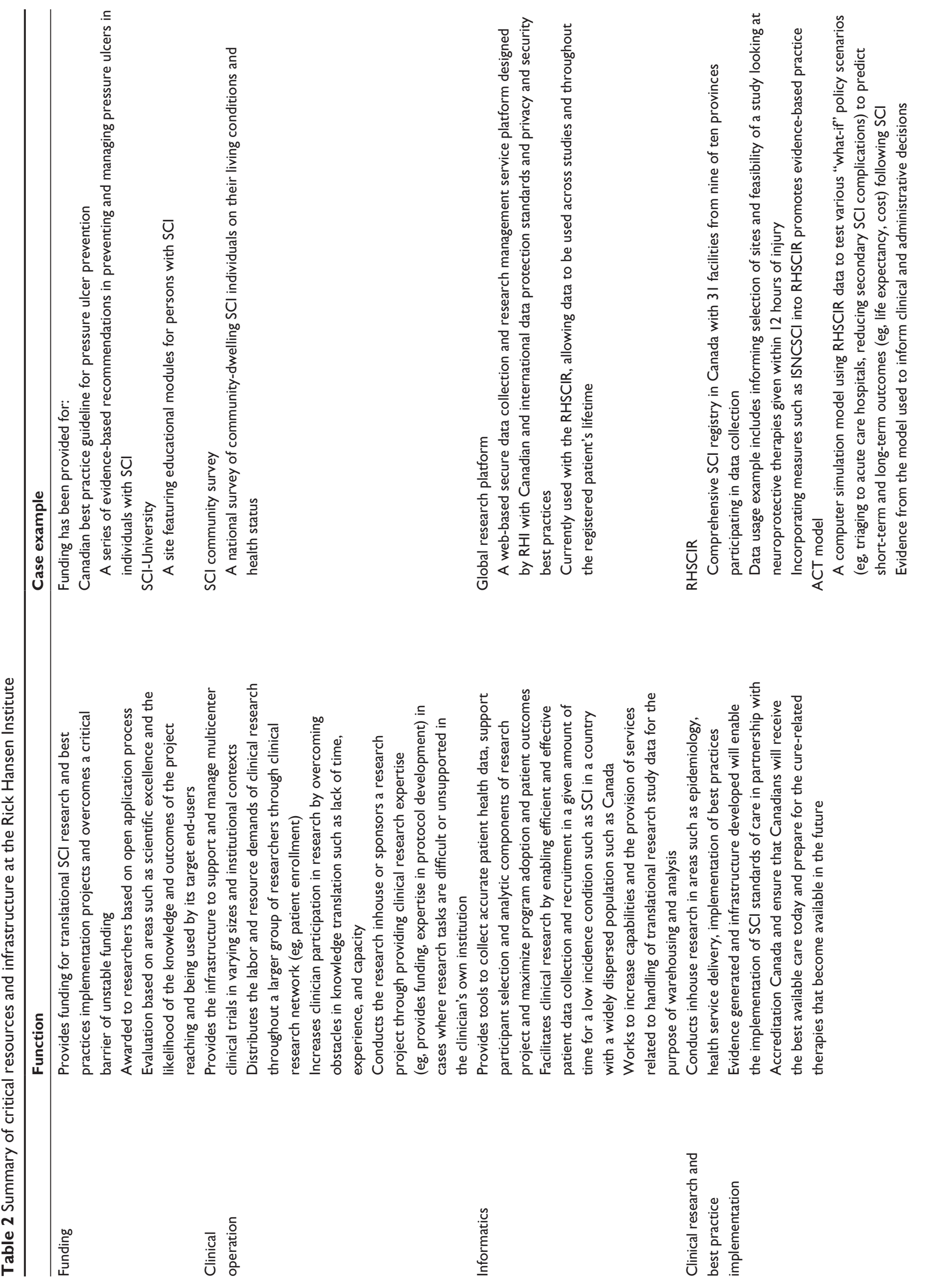



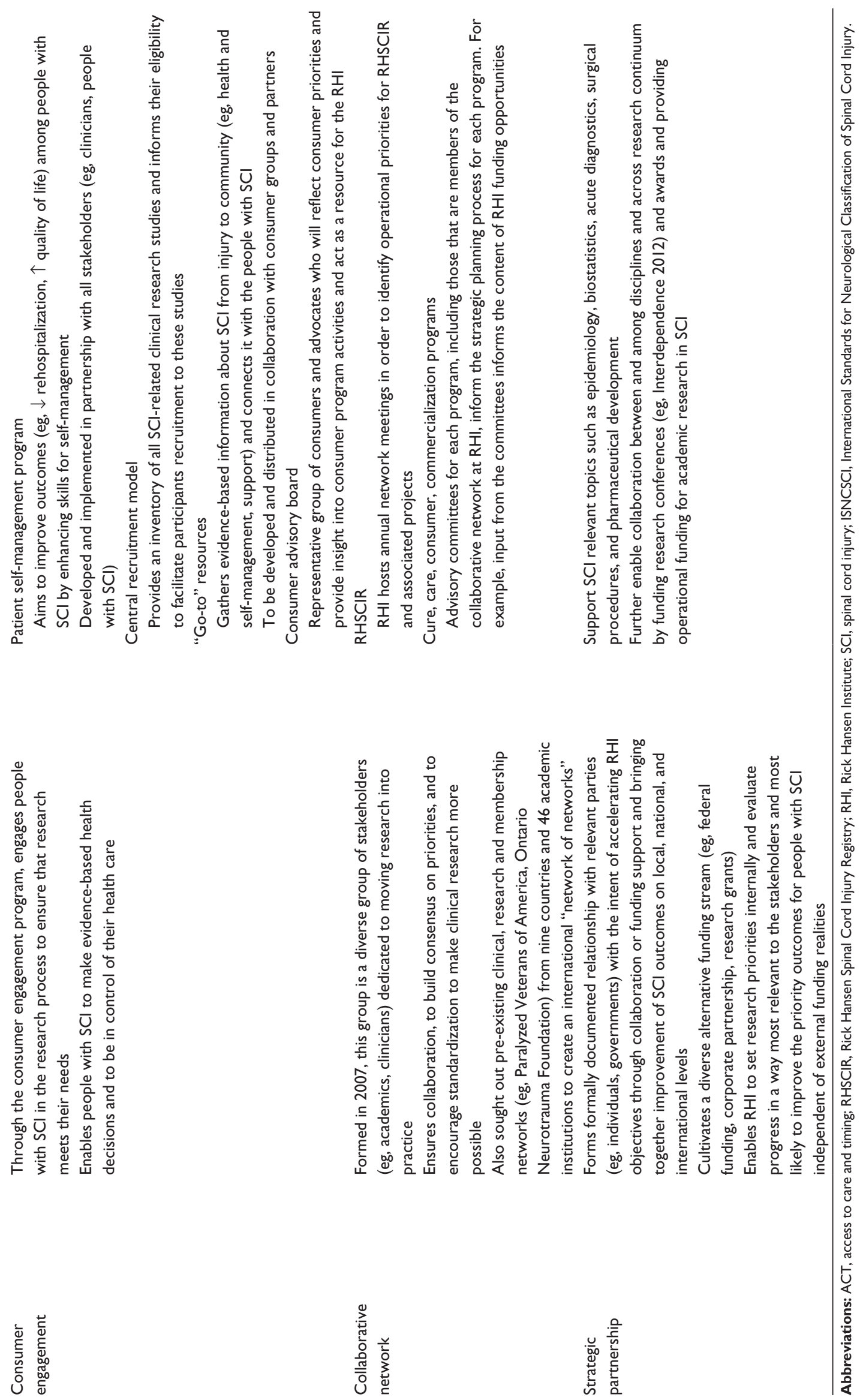


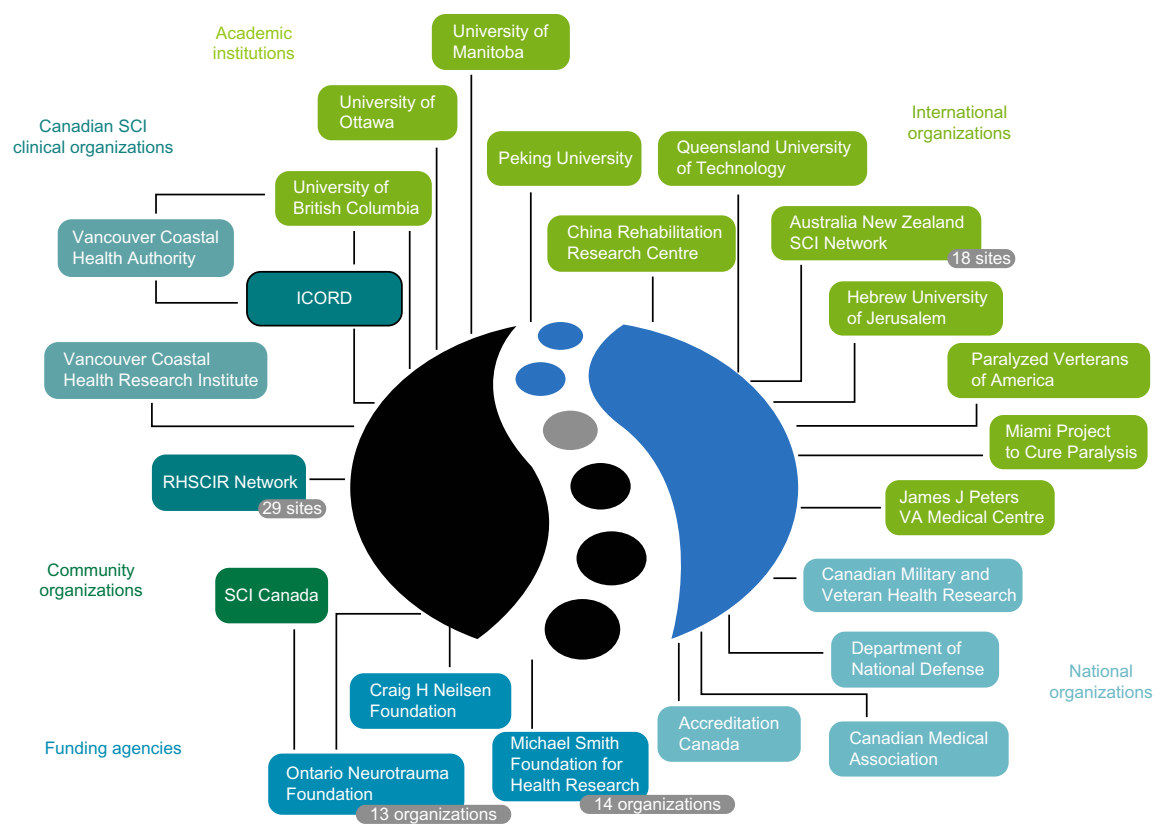

Figure 3 Network of individuals, organizations, and networks at the Rick Hansen Institute.

Abbreviations: ICORD, International Collaboration On Repair Discoveries; RHSCIR, Rick Hansen Spinal Cord Injury Registry; SCI, spinal cord injury.

At the output and immediate outcome levels, performance measurement data are collected primarily by project teams, and are aggregated in a central results database. See Table 3 for examples of performance indicators at the output and immediate outcome levels. Relevant performance indicators at the ultimate outcome level are continuing to be developed, but will focus on population health outcomes and systemwide cost savings, likely to be collected from the RHI Rick Hansen Spinal Cord Injury Registry (RHSCIR), ${ }^{33}$ and health economic studies and independent evaluations sponsored by RHI.
Evaluations at RHI are undertaken within the context of the RHI logic model, and support efforts to understand the effectiveness of the praxis model. Evaluation of implementation activities is done through the lens of a comprehensive framework of implementation. ${ }^{34}$ Evaluation of research impact is primarily done through case studies identifying specific changes brought about by the research, understanding that research can have disparate outcomes; for example, the results of research may influence policy decisions, may influence care in a clinical setting, or may accelerate further research. Within its current 5-year strategic plan, RHI will

Table 3 Examples of performance indicators at the output and immediate outcome level

\begin{tabular}{lll}
\hline Result & Examples of performance indicators & Data source \\
\hline Output level indicators & Number of publications, conference presentations, other knowledge products & Project reporting \\
& Amount of leveraged funds & Project reporting \\
& Number of research studies supported, by type & Project reporting \\
& Number of sites participating in key projects & Project reporting \\
& Number of policy-makers, researchers, health professionals, people with SCI, & Project reporting \\
& and other stakeholders engaged in RHI projects, by type and location & Project reporting \\
Immediate outcome & Number of studies supported by the GRP at RHI & Grant reporting \\
indicators & Number of new research studies enabled by RHI products/services & Project reporting \\
& (data accessed from RHI sources, data linkage enabled by GRP) & Facilities/accreditation \\
& Evidence of retention and success among supported researchers (qualitative case studies) & Canada \\
& Percent of sites accredited among RHI network sites & Network survey \\
& Number/percent of clinicians self-reporting use of evidence-based practices & Project reporting \\
\hline
\end{tabular}

Abbreviations: GRP, Global Research Platform; RHI, Rick Hansen Institute; SCI, spinal cord injury. 
undertake a mid-term evaluation of its activities in 2015, and an impact evaluation in 2018.

\section{Praxis model in action for prevention of pressure ulcers}

The praxis model has direct application in many research and intervention practices in the setting of SCI, including prevention of pressure ulcers. The development of a pressure ulcer is a common secondary complication following $\mathrm{SCI}$, with a lifetime incidence of up to $80 \% .{ }^{35-37}$ Pressure ulcers often lead to recurrent hospitalizations, with average cost per individual with a pressure ulcer as high as CAD $\$ 4,757$ per month ${ }^{38}$ as well as a negative impact on quality of life. ${ }^{35}$ Several factors influence the development of a pressure ulcer, ${ }^{39}$ and some are preventable. If symptoms are identified promptly and treated appropriately, this economic burden could be reduced, with improved patient outcomes.

Several innovations for the prevention and treatment of pressure ulcers exist, and there is a solid body of evidence supporting practice in management of pressure ulcers; however, systemic, practical, and regulatory obstacles exist in implementing appropriate management. These obstacles represent "valleys of death" in the contexts of both basic to clinical research and clinical knowledge to practice. Researchers recently examined barriers to implementation of clinical practice guidelines in the management of pressure ulcers and found that the barriers included organizational factors, lack of education/training, and lack of resources, a need for better research evidence, and the complexity of the guideline design. ${ }^{8}$ Prevention and management of pressure ulcers was identified by the RHI clinical network as a costly problem with clear areas for progress. Figure 4 illustrates the cycle of knowledge for pressure ulcers, which would fit within the praxis model after the clinical translational research and practice "valley of death".

\section{Phase I: environmental scan}

Pressure ulcers are present throughout the continuum of care. Therefore, any effective plan must engage providers in acute, rehabilitation, and community care in order to prevent pressure ulcers and reduce morbidity. Members of the RHI clinical research network who are involved in rehabilitation services conducted the first ever national survey of Canadian SCI-related rehabilitation practice in order to obtain a snapshot of current SCI rehabilitation service delivery, care providers, and research capacity. A rehabilitation environmental scan atlas, recently produced for administrators, policy-makers, researchers, and clinicians, summarized best practices, gaps, and status reports on rehabilitation care, including management of pressure

Translational valley of death - knowledge cycle

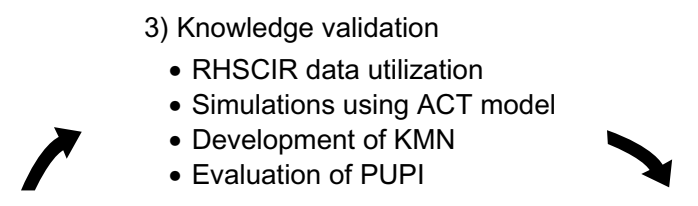

2) Knowledge generation and synthesis

- SCIRE systematic reviews

- RHSCIR and SCl-community survey data utilization

- Development of PUPI

- Development of clinical practice guidelines
4) Implementation

- RHSCIR and SCl-community survey data utilization

- Best-practice implementation through accreditation Canada and KMN

- Best-practice implementation using SCI-U by persons with $\mathrm{SCl}$

- Primary care physician education through Actionable Nuggets program

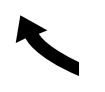

1) Environmental scan

- Rehab E-scan

- RHSCIR and SCl-community survey data collection

Figure 4 Knowledge cycle of the praxis model to cross the "valley of death" from clinical research to health care delivery for addressing pressure ulcers as a secondary complication of SCl.

Abbreviations: ACT, access to care and timing; E-Scan, environmental scan; KMN, knowledge mobilization network; PUPI, Pressure Ulcer Prevention Initiative; RHSCIR, Rick Hansen Spinal Cord Injury Registry; SCl, spinal cord injury; SCIRE, Spinal Cord Injury Rehabilitation Evidence; SCI-U, Spinal Cord Injury University. 
ulcers. ${ }^{40}$ The results found that SCI skin and wound care services in rehabilitation facilities varied widely across Canada. It was noted that the challenges of interdisciplinary teams have made evidence-based practice difficult and have resulted in individuals reverting to solo practice. This scan also noted several therapies well supported by research that were not being used in the management or prevention of pressure ulcers in patients with SCI.

To gain a further understanding of the current state of pressure ulcer management with respect to individuals with SCI, two national sources of patient data on SCI are currently gathering information on occurrence of pressure ulcers, characteristics, care, and patient experiences: the RHSCIR gathers data on pressure ulcers as part of its ongoing surveillance of individuals with new SCI, and the SCI Community Survey of individuals with SCI living within the community, ${ }^{41}$ supported by the RHI through funding and clinical operations support, records information on patients surveyed regarding their experiences of pressure ulcers. These invaluable sources of data provide a "scan" or a picture of pressure ulcers in SCI in Canada to inform the next steps in the praxis knowledge cycle and move innovations into the clinical setting. Ultimately, these knowledge tools arm researchers, care providers, and decision-makers with the knowledge they need to identify areas in need of further research, issues in their own practice in need of improvement, and conversely, areas of excellence to be evaluated and shared.

\section{Phase 2: generation and synthesis of knowledge}

As environmental scans start to indicate the status and gaps in management of pressure ulcers in Canada, the focus must be on answering some of the key questions indicated by the clinical problem of pressure ulcers and must be synthesized in manageable and useful ways. To synthesize the current research evidence underlying interventions and treatments for pressure ulcers, the RHI has funded the Spinal Cord Injury Rehabilitation Evidence project, ${ }^{42}$ which contains a systematic review of the management of pressure ulcers. In an effort to prevent pressure ulcers and improve treatment, RHI researchers worked with clinicians to evaluate the Pressure Ulcer Prevention Initiative, which screens and manages patients with SCI in acute care (Cobb et al, unpublished data, 2014). Following this initiative, all patients with SCI are screened by specially trained occupational therapists. The goal is to monitor closely the incidence and progression of pressure ulcers, evaluate the effectiveness of interventions such as pressure-relieving mattresses, and report on the long-term patient outcomes following discharge into the community.

Furthering knowledge generation and synthesis activities for pressure ulcers, the RHI and the Ontario Neurotrauma Foundation have funded the development of the Canadian Best Practice Guidelines for prevention, assessment, and treatment of pressure ulcers in people with SCI. Additionally, the data collected in the RHSCIR study and the SCI community survey will be utilized to generate knowledge regarding pressure ulcers throughout the continuum of care.

\section{Phase 3: validation of knowledge}

Evaluating the therapies and tools developed within the generation and synthesis phase is an important part of the knowledge cycle. The uptake of new approaches requires validation within the SCI research field. After development of novel SCI pressure ulcer monitoring tools for rehabilitation and acute contexts, initiatives such as Pressure Ulcer Prevention Initiative will need to be evaluated as a part of the validation phase. This phase also involves piloting projects in new contexts based on previous research, including the pilot testing of a tele-health pressure ulcer clinic for individuals in remote areas to access specialized care. A knowledge mobilization network was also piloted as a means to develop and implement best practice guidelines for prevention, assessment, and treatment of pressure ulcers in people with SCI.

Using data gathered through the RHSCIR, a simulation model of the continuum of care for patients with traumatic SCI was created as a novel approach to look at the access and timing of care for traumatic SCI in Canada. ${ }^{43}$ This model will be used to evaluate the impact of new policy initiatives on patient and system outcomes, and allows RHI researchers to test different strategies for management and treatment of pressure ulcers to estimate outcomes based on certain interventions. ${ }^{43}$ The results of these simulations will be valuable when analyzing the direct and indirect effects of pressure ulcer initiatives throughout the care continuum and optimizing future decisions for people with traumatic SCI.

\section{Phase 4: implementation}

Patient education is an important component in prevention of pressure ulcers. A unique e-learning tool sponsored in part by the RHI, the SCI-University is a site featuring educational modules for persons with SCI. Part of this project involves evaluation of knowledge uptake, so that modules can continually be optimized for SCI consumer needs. In order to 
assist primary care physicians to incorporate best practices for SCI in primary care, the RHI's Actionable Nuggets program developed a series of information cards accredited as continuing medical education by the Canadian Medical Association.

The accreditation of health care facilities by a recognized body is a common approach to validate the implementation of best practices, and provides validation and credibility to institutions. The RHI has partnered with Accreditation Canada to develop standards and an accreditation program for SCI to target all hospitals and rehabilitation facilities providing care to people with SCI across Canada. This will be the first accreditation program for acute care in Canada, ${ }^{44}$ and will integrate SCI-specific pressure ulcer guidelines into practice through accredited Canadian SCI institutions. Developing and implementing a standard of SCI care to be accredited in acute and rehabilitation hospitals throughout Canada is a key medium for implementation of best practices. This also serves as a vital part of the RHI's overall strategy to bridge the second "valley of death" by creating a network in which clinical advances can be disseminated and implemented across the country.

Once implementation strategies are integrated into practice, it is crucial to evaluate the acceptance of these strategies and report on the success of the change. RHI recognizes the importance of developing an infrastructure of leaders in knowledge translation for effective dissemination, behavior change, and promotion of uptake of knowledge and best practice guidelines. The knowledge mobilization network, whereby leaders work collectively to implement guidelines in real-world practice, will be used to assess the process of implementing pressure ulcer guidelines and evaluate the effectiveness of knowledge brokers on changing clinical practice.

RHI was in the best position to assume the leadership role in the development and application of the praxis model. The institutions and organizations within the RHI's collaborative network tend to focus on discrete areas of the continuum of SCI research and treatment, or have a specific regional focus (eg, provincial). The RHI takes a broader view, both in terms of the SCI continuum and from a regional perspective. Furthermore, the ability of the RHI to provide critical resources and infrastructure to its collaborative network and strategic partners enables it to direct how the resources are utilized. In other words, RHI is able to lead both the manner and process in which resources are utilized among its collaborative network. However, it was important for RHI to develop support among its collaborative network within the concept of the model and how resources would be allocated across the network. Therefore, it is critical that the praxis model is applied in a transparent manner.

\section{Future directions}

The praxis model has been developed and put into action by the RHI in an effort to bridge the "valleys of death" in translational research and ultimately improve the quality of care received by people with SCI. This is a constantly evolving model, which adapts with each lesson learned to better serve its purpose. At this time, there has not been a formal evaluation conducted to examine development, operation, and outcomes produced by the praxis model. Such an evaluation is planned for a few years' time in order to collect data prospectively according to the performance measures presented in this paper and evaluate the findings objectively. This evaluation will inform the operationalization of a model to bridge the gap in translational research in SCI, which could be adapted to work in other health research fields.

\section{Conclusion}

"Valleys of death" in research and implementation continue to limit the passage of research innovations into clinical or commercial use for the purpose of improving patient outcomes, and remain a critical obstacle to health research and patient benefit. RHI has developed the praxis model, an innovative solution to address these obstacles in translational research. This model is proving to be viable for bridging the "valleys of death" in the translation of SCI research. The praxis model strives to lead collaboration across the global SCI community through a coordinated program strategy (cure, care, consumer engagement, and commercialization), a four-phase knowledge cycle (environmental scan, knowledge generation and synthesis, knowledge validation, and implementation), and comprehensive resources and infrastructure (funding, clinical research operations, informatics, clinical research and best practice implementation, consumer engagement, and collaborative network and strategic partnerships). As the praxis model continues to be refined and implemented at the RHI, it may assist in prioritizing translational research and knowledge action cycles from basic research to clinical settings and from clinical research to implementation and adoption of practices, as well as informing more appropriate policies. These latter areas will capture the change in practice behaviors and improvement in the outcomes for people with SCI. It is also proposed that this praxis model may be 
transferable and applicable to other organizations dealing with similar translational research challenges regarding "valleys of death".

\section{Acknowledgments}

The Rick Hansen Institute would like to acknowledge its primary funding partners for their generous support: Western Economic Diversification, Health Canada, and the Rick Hansen Foundation. RHI would like also to acknowledge Tung Chan, a member of the RHI board of directors, for introducing the term "praxis", and Sophia Park, research assistant at RHI, for organizing the references and final formatting of this paper.

\section{Disclosure}

The authors of this publication are employees of the Rick Hansen Institute, with the exception of KKB, who is the chair of the translational research advisory committee at the RHI.

\section{References}

1. Dryden DM, Saunders LD, Rowe BH, et al. Utilization of health services following spinal cord injury: a 6-year follow-up study. Spinal Cord. 2004;42(9):513-525.

2. Kennedy P, Smithson E, McClelland M, Short D, Royle J, Wilson C. Life satisfaction, appraisals and functional outcomes in spinal cord-injured people living in the community. Spinal Cord. 2010;48(2):144-148.

3. Noonan V, Fingas M, Farry A, et al. The incidence and prevalence of spinal cord injury in Canada: a national perspective. Neuroepidemiology. 2012;38(4):219-226.

4. Krueger H, Noonan VK, Trenaman LM, Joshi P, Rivers C. The economic burden of traumatic spinal cord injury in Canada. Chronic Dis Inj Can. 2013;33(3):113-122.

5. Winslow C, Bode RK, Felton D, Chen D, Meyer PR Jr. Impact of respiratory complications on length of stay and hospital costs in acute cervical spine injury. Chest. 2002;121(5):1548-1554.

6. Wing PC. Early acute management in adults with spinal cord injury: a clinical practice guideline for health-care providers. Who should read it? J Spinal Cord Med. 2008;31(4):360.

7. Thuret S, Moon LD, Gage FH. Therapeutic interventions after spinal cord injury. Nat Rev Neurosci. 2006;7(8):628-643.

8. Thomason SS, Evitt CP, Harrow JJ, et al. Providers' perceptions of spinal cord injury pressure ulcer guidelines. J Spinal Cord Med. 2007;30(2):117-126.

9. Goetz LL, Nelson AL, Guihan M, et al. Provider adherence to implementation of clinical practice guidelines for neurogenic bowel in adults with spinal cord injury. J Spinal Cord Med. 2005;28(5): 394-406.

10. Burns SP, Nelson AL, Bosshart HT, et al. Implementation of clinical practice guidelines for prevention of thromboembolism in spinal cord injury. J Spinal Cord Med. 2005;28(1):33-42.

11. Westfall JM, Mold J, Fagnan L. Practice-based research - "Blue Highways" on the NIH roadmap. JAMA. 2007;297(4):403-406.

12. Morris ZS, Wooding S, Grant J. The answer is 17 years, what is the question: understanding time lags in translational research. $J R S o c$ Med. 2011;104(12):510-520.

13. Canadian Institutes of Health Research. Strategy for patient-oriented research. Available from: http://www.cihr-irsc.gc.ca/e/44000.html\#a2.2. Accessed November 11, 2011.
14. Markham SK. Moving technologies from lab to market. Res Technol Manage. 2002;45(6):31-42.

15. Chimera Research Group. Crossing the biotech 'valley of death': from innovation to cure. Available from: http://seekingalpha.com/ article/224005-crossing-the-biotech-valley-of-death-from-innovationto-cure. Accessed February 28, 2014.

16. Butler D. Translational research: crossing the valley of death. Nature. 2008;453(7197):840-842.

17. Bornstein D. Helping new drugs out of research's 'valley of death'. Available from: http://opinionator.blogs.nytimes.com/2011/05/02/ helping-new-drugs-out-of-academias-valley-of-death/. Accessed February 28, 2014.

18. Sung NS, Crowley WF Jr, Genel M, et al. Central challenges facing the national clinical research enterprise. JAMA. 2003;289(10): 1278-1287.

19. Dorsey ER, Thompson JP, Carrasco M, et al. Financing of US biomedical research and new drug approvals across therapeutic areas. PLoS One. 2009;4(9):e7015.

20. Yusuf S, Cairns J. The perilous state of independent randomized clinical trials and related applied research in Canada. CMAJ. 2012;184(18):1997-2002.

21. Lang ES, Wyer PC, Haynes RB. Knowledge translation: closing the evidence-to-practice gap. Ann Emerg Med. 2007;49(3):355-363.

22. Reis SE, McDonald MC, Byers SJ. Crossing the research valleys of death: the University of Pittsburgh approach. Clin Transl Sci. 2008;1(1):9-10.

23. Richards JS. Collaborative research in the model spinal cord injury systems: process and outcomes. J Spinal Cord Med. 2002;25(4): 331-334.

24. "Praxis." Oxford Dictionary. Oxford, UK: Oxford University Press; 2010.

25. Blackburn S. Oxford Dictionary of Philosophy. Oxford, UK: Oxford University Press; 1996.

26. Graham ID, Logan J, Harrison MB, et al. Lost in knowledge translation: time for a map? J Contin Educ Health Prof. 2006;26(1):13-24.

27. Haynes RB. Of studies, syntheses, synopses, and systems: the " $4 \mathrm{~S}$ " evolution of services for finding current best evidence. APC J Club. 2001;134:A11-A13.

28. Eng JJ, Teasell RW, Miller WC, et al. Spinal Cord Injury Rehabilitation Evidence (SCIRE). Available from: http://www.scireproject.com./ rehabilitation-evidence. Accessed February 28, 2014.

29. Bhattacharyya O, Anita McGahan MBA, Mitchell W, et al. A review of best practices in performance reporting: developing a broad hierarchy of performance measures. Center for Health Market Innovations Available from: http://healthmarketinnovations.org/document/reviewbest-practices-performance-reporting-developing-broad-hierarchyperformance-measures. Accessed January 29, 2013.

30. Mayne J. [Reporting on outcomes: setting performance expectations and telling performance stories]. Can J Program Eval. 2004;19(1):31-60. French.

31. Perrin B. Moving from outputs to outcomes: practical advice from governments around the world. 2006. Available from: http://siteresources.worldbank.org/CDFINTRANET/Resources/PerrinReport.pdf. Accessed March 2, 2014.

32. Treasury Board Secretariat. Supporting effective evaluations: a guide to developing performance measurement strategies. Available from: http:// www.tbs-sct.gc.ca/cee/dpms-esmr/dpms-esmr00-eng.asp. Accessed January 29, 2014.

33. Noonan VK, Kwon BK, Soril L, et al; RHSCIR Network. The Rick Hansen Spinal Cord Injury Registry (RHSCIR): a national patientregistry. Spinal Cord. 2012;50(1):22-27.

34. Damschroder LJ, Aron DC, Keith RE, Kirsh SR, Alexander JA, Lowery JC. Fostering implementation of health services research findings into practice: a consolidated framework for advancing implementation science. Implement Sci. 2009;4:50.

35. Krause JS. Skin sores after spinal cord injury: relationship to life adjustment. Spinal Cord. 1998;36(1):51-56. 
36. Walter JS, Sacks J, Othman R, et al. A database of self-reported secondary medical problems among VA spinal cord injury patients: its role in clinical care and management. J Rehabil Res Dev. 2002;39(1):53-61.

37. Garber SL, Rintala DH. Pressure ulcers in veterans with spinal cord injury: a retrospective study. J Rehabil Res Dev. 2003;40(5):433-441.

38. Chan BC, Nanwa N, Mittmann N, et al. The average cost of pressure ulcer management in a community dwelling spinal cord injury population. Int Wound J. 2013;10(4):431-440.

39. Byrne DW, Salzberg CA. Major risk factors for pressure ulcers in the spinal cord disabled: a literature review. Spinal Cord. 1996;34(5): 255-263.

40. Craven C, Verrier M, Balioussis C, et al. Rehabilitation Environmental Scan Atlas: Capturing Capacity in Canadian SCI Rehabilitation. Vancouver, BC, Canada: Rick Hansen Institute; 2012.

41. Noreau L, Adair B, Boschen K, et al. Spinal Cord Injury Community Survey: Participants Report - Traumatic Injuries. Vancouver: Rick Hansen Institute; 2013. Available from: http://www.scisn.org/rhi2013new/ images/stories/SCI\%20Survey/Participants_report_TSCI_ENG.pdf. Accessed March 20, 2014.
42. Regan MA, Teasell RW, Wolfe DL, et al. A systematic review of therapeutic interventions for pressure ulcers after spinal cord injury. Arch Phys Med Rehabil. 2009;90(2):213-231.

43. Atkins D, Noonan VK, Santos A, et al. Secondary complications in SCI across the continuum: using operations research to predict the impact and optimize management strategies. Top Spinal Cord Inj Rehabil. 2012;18(1):57.

44. Accreditation Canada. Rick Hansen Institute and Accreditation Canada to develop first ever standards for spinal cord injury care and services in Canada. Available from: http:/www.rickhanseninstitute.org/49-mediaroom/media-room/256-for-immediate-release. Accessed March 2, 2014
Journal of Healthcare Leadership

\section{Publish your work in this journal}

The Journal of Healthcare Leadership is an international, peer-reviewed, open access journal focusing on leadership for the health profession. The journal is committed to the rapid publication of research focusing on but not limited to: Healthcare policy and law; Theoretical and practical aspects healthcare delivery; Interactions between healthcare and society and evidence-based practices;

\section{Dovepress}

Interdisciplinary decision-making; Philosophical and ethical issues; Hazard management; Research and opinion for health leadership; Leadership assessment. The manuscript management system is completely online and includes a very quick and fair peer-review system. Visit http://www.dovepress.com/ testimonials.php to read real quotes from published authors.

Submit your manuscript here: http://www.dovepress.com/journal-of-healthcare-leadership-journal 